\title{
Missed Preoperative Diagnosis of a Double Gallbladder with Cholelithiasis in the Era of Advanced Imaging: A Rare Case Report
}

\author{
Sadaf Ali, Sajjad A Mallik, Omar J Shah Atthar B khan \\ Department of Surgical gastroenterology, SKIMS, Soura, Srinagar J\&K, India;
}

\section{A B STRACT}

Introduction: Double gallbladder is one of the rare congenital anomaly of the gallbladder and a surgeon may come across it once in life time. Case Presentation: We present a case of double gall bladder separated by a common wall. This case was neither diagnosed nor suspected by radiologist on routine ultrasound. The patient was reported as a usual case of cholelithiasis and an inoperative surprising rare surgical anomaly of gall bladder was observed. Conclusion: This congenital anomaly can present as a surprise on the operating table and may pose a difficult cholecystectomy.

Key words: Double Gall bladder, cholelithiasis, imaging, case report

\section{INTRODUCTION}

Gall bladder anomalies are not that rare but of the list of anomalies reported a double gall bladder is extremely rare and one may come across it once in a life time. We report this case of double gall bladder which came as a surprise to us on operating table. As the disease was not expected preoperatively we had difficulty in performing the so assumed routine and easy abdominal surgery called cholecystectomy. Present literature describes incidence of double gall bladder to be 0.25 per 1000 autopsy series. Two types of double gall bladders known include Type1: having two compartments separated by a membrane with a single cystic duct and Type 2: having two distinct compartments with two cystic ducts.

Introduction to be supported with scientific literature, include proper citations

\section{CASE SUMIMARY}

A 35 year old lady presented to our out patient department with history of pain right upper abdomen of 6 months duration. She gave history of pain being of moderate

\section{Address for correspondence:}

Email:sadafajaz@yahoo.com

DOI: 10.5530/ijmedph.2.2011.10 intensity, getting aggravated after meals and radiated to her right shoulder blade. Her clinical examination did not reveal any icterus, pallor or any other positive physical finding. Her systemic examination revealed a normal Abdomen, Respiratory, Cardiovascular and Neurological system. An initial diagnosis of non ulcer dyspepsia was made and an ultrasound was simultaneously advised to look for cholelithiasis. This patient subsequently reported back to our department, with ultrasound abdomen suggestive of cholelithiasis. The patient was further worked up with liver function test and other baseline investigations which were within normal limit. And she was planned for an elective open cholecystectomy.

The surprise came on table as her cholecystectomy posed some problems while dissection of Callots triangle as the junction of cystic duct with common hepatic duct appeared to be wide. An initial impression of possibility of Mirrizzi's syndrome was made and a decision to operate with fundus first method was taken. The gall bladder was dissected out from fundus up to 1 centimetre away from expected area of junction of cystic duct with common bile duct, and then the gall bladder was resected and removed (Fig. 1, 2). The specimen inspected revealed a double gall bladder with one compartment having cholesterol stones and other showing features of cholesterosis (Fig. 3). After confirming the diagnosis rest of the stump was also dissected out and the two ducts having a common wall were ligated together at appropriate distance from common hepatic- cystic duct junction (Fig. 4). 


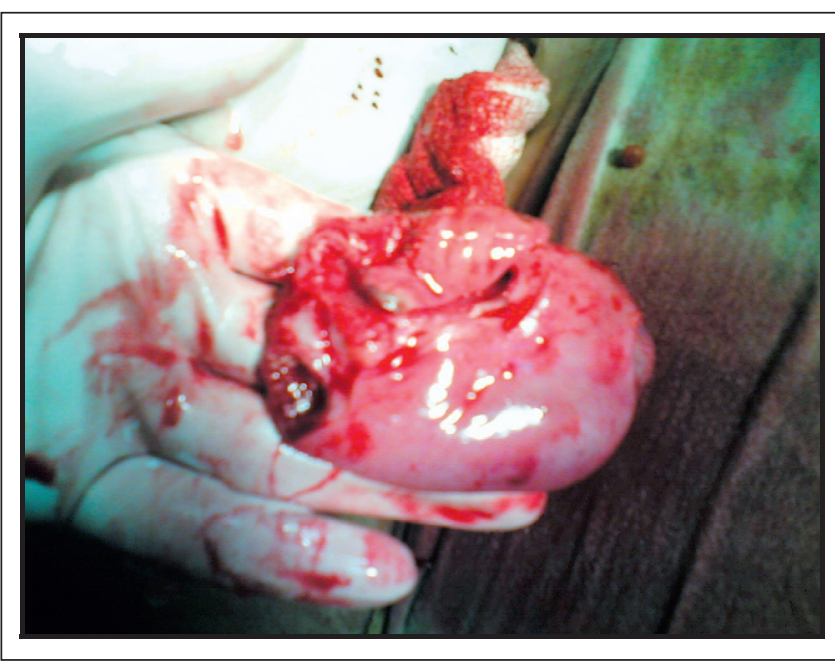

Figure 1: Specimen of resected Gallbladder

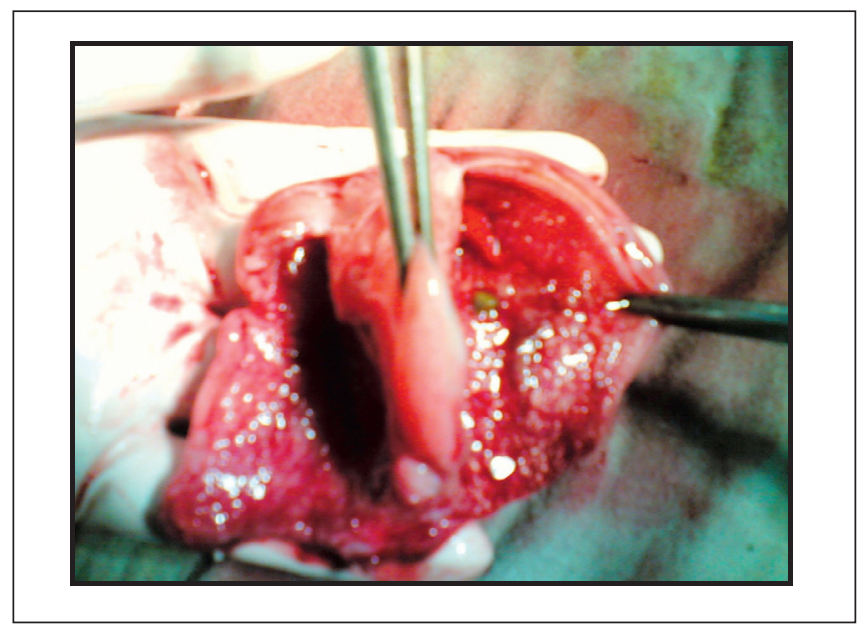

Figure 3:Two compartments opened displaying pathology

\section{DISCUSSION}

Duplication of the gallbladder is a rare anomaly of the biliary tract, occurring at a rate of $0.25 / 1,000$ in one autopsy series. ${ }^{1}$ Embryologically this occurs rarely when the gallbladder primordial bifurcates and results in duplication of gallbladder in $5^{\text {th }}$ or $6^{\text {th }}$ week of life. There are a wide range of congenital anomalies of the Gallbladder is noticed and reported in literature ranging from double gallbladder to the complete absence of the gall bladder.

There are two types of double gall bladder: 1. Gall bladder with two adjacent lobes that are separated by a soft membrane - usually having a single common cystic duct; 2. And the other variety that involves the presence of two distinctive, separate organs - that usually have separate ducts

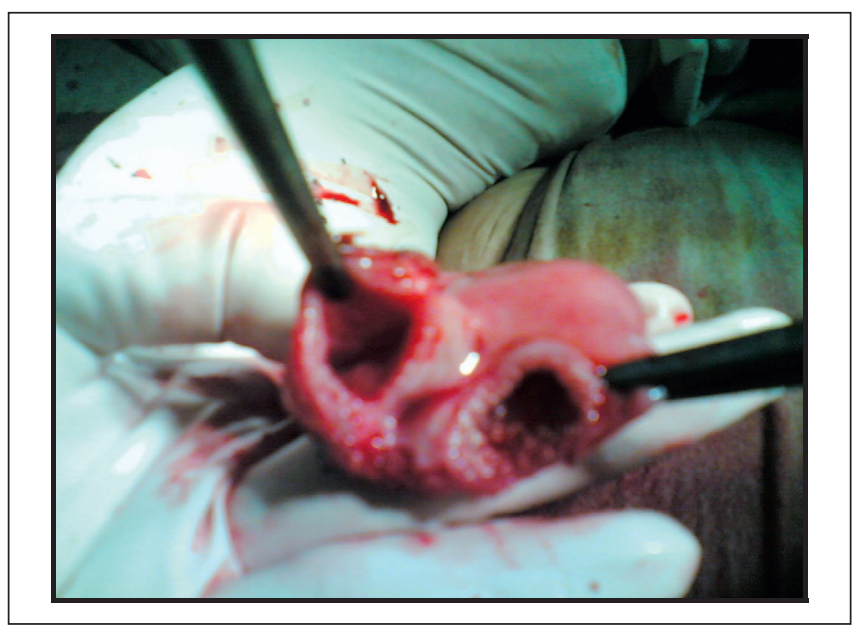

Figure 2: Two lumens of the Double Gallbladder

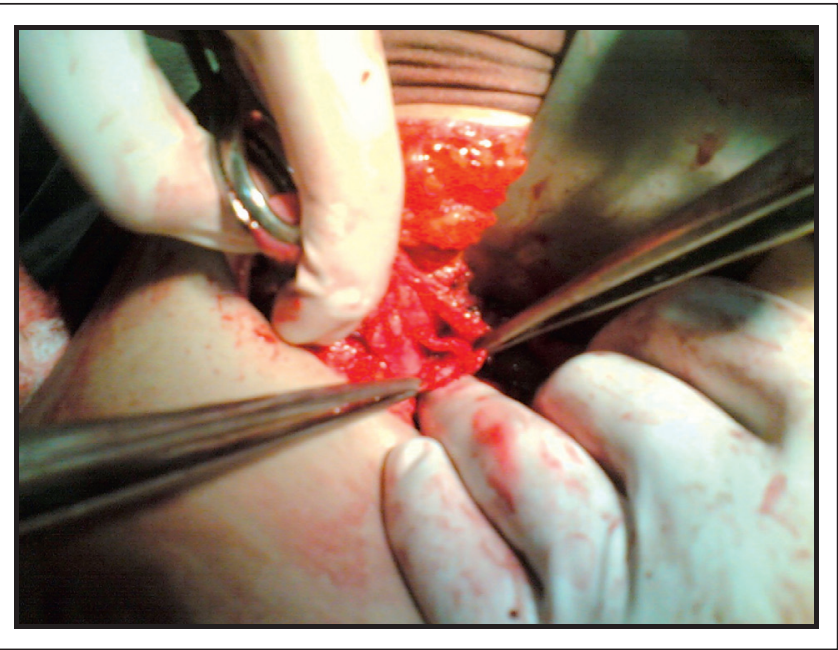

Figure 4: Stump of the cystic ducts

The gall bladder disease can either affect one lobe or both lobes of the double gall bladder. However, both cases require complete surgical removal of the organ.

The anatomical location of a double gallbladder is variable; most gallbladders share a common peritoneal coat and are usually adjacent to each other. Occasionally, one gallbladder could be entirely intrahepatic or even sub-hepatic. True gallbladder duplication can either have a common cystic duct, arterial supply or separate cystic ducts and blood supply.

Timely diagnosis of such congenital anomalies of the gall bladder is extremely important in order to carefully plan the surgical intervention. Although gall bladder surgery is considered to be a routine surgical procedure, patients with congenital anomalies require additional operative care to avoid inadvertent complications as injury to the common bile duct or finding other gall bladder subsequent to the surgery. 
Like present case other authors have also reported different pathology in the two compartments of the Double Gall bladder. ${ }^{2,3}$ Gallstone is the commonest complication occurring in one or both gallbladders.

There is no increase in the incidence of disease in double gallbladder, so prophylactic cholecystectomy in an asymptomatic patient is not recommended. ${ }^{4}$ It is important to diagnose this anomaly pre-operatively because the second gallbladder may be overlooked during surgery. ${ }^{5}$

Although in the past these anomalies couldn't be revealed by traditional methods of diagnosis, nowadays it can be easily diagnosed by magnetic resonance imaging, ${ }^{6}$ computerized tomography, or even by an ultrasound performed by an experienced radiologist.

\section{CONCLUSION}

We have come across a case of double gallbladder on table as routine ultrasound did not pick up the same. This conveys a message that even in present era of advanced imaging gadgets a double gall bladder may be overlooked and surgeons should keep this entity in mind while performing the so called commonest operation in surgical practice.

\section{REFERENCES}

1. Boyden EA.The accessory gallbladder: an embryological and comparative study of aberrant biliary vesicles occurring in man and the domestic mammals. Am J Anat; 1926, 38:177-231.

2. A Gautam, S Kala, M Kumar, CL Sharma. Double gall bladder with two disease processes. Indian j of gastroentrol, 18:4:179.

3. R Vijayaraghavan, Charalingappa S Belagavi.Double gallbladder with different disease entities: A case report. Journal of min acess surg, 2006, 2:1:23-26.

4. Gigot J, Van Beers B, Goncette L, Etienne J. Collard A, Jadoul P, Therasse A, Otte JB,Kestens P. Laparoscopic treatment of gallbladder duplication-A plea for removal of both gallbladder. Surg Endosc 1997; 11; 479-82.

5. Puneet, Satyendra Kumar Tiwary, Sameer Agarwal.Double Gallbladder. Internet j of gastroentrol, 1528-8323.

6. Mazziotti S, Minutoli F, Blandino A, Vinci S, Salamone I, Gaeta M. Gallbladder duplication: MR Cholangiography demonstration. Abdom Imaging 2001; 26; 287-9. 